\title{
Rotatory multiplier
}

\section{R. Hare M.D.}

To cite this article: R. Hare M.D. (1837) Rotatory multiplier, Philosophical Magazine Series 3, 11:67, 327-327, DOI: 10.1080/14786443708649288

To link to this article: http://dx.doi.org/10.1080/14786443708649288

$$
\text { 曲 Published online: } 01 \text { Jun } 2009 .
$$

Submit your article to this journal

LII Article views: 2

Q View related articles $₫$ 
milarly prepared, to produce the synthesis of ammonia, either when substituted for the sponge, in the experiment above described, or carried red hot from a fire and passed into a bell glass containing the mixture over mercury.

In fact a piece of charcoal soaked in a solution of chloride of platinum, (choroplatinic acid,) produced effects analogous to the platinated asbestus.

To produce platinated asbestus, it was found sufficient to dip it in liquid chloride of platinum, and then subject the mass to a red heat in a common fire.

ROTATORY MULTIPLIER. BY R. HARE, M.D.

Dr. Hare has contrived a rotatory multiplier in the following way: Just as the needle, in oscillating, reaches its appropriate position in the meridian, by means of two pins proceeding from it perpendicularly so as to enter two mercurial globules, it completes a circuit through the coil ; one end of which terminates in one of the globules. The other end of the coil of the multiplier communicates with one pole of a galvanic pair, of which the other pole communicates with the other globule. The needle is thus subjected to an impulse which causes it to revolve until it receives another impulse by the same process repeated. Each revolution therefore causes an impulse which is productive of a succeeding revolution so long as the galvanic reaction is sustained.

The construction was subsequently improved by employing two coils of copper wire of equal length, separated by paper and varnish, one being wound over the other. They were so arranged that the needle receives two impulses in each revolution, one as above described, the other when its north pole points to the south. Again, two needles associated so as to form a cross are made to complete a circuit every fourth of a revolution, and thus to receive four impulses in one revolution.

ME'TEOROLOGICAL OBSERVATIONS FOR JULY 1837.

Chiswick.-July 1. Cloudy : fine: clear and cold at night. 2, 3. Very dry. 4-12. Very fine. 13. Overcast. 14. Clondy and fine, heavy showers. 15. Showery. 16. Very fine. 17, 18. Clondy and fine. 19. Very fine. 20. Fine. $21-26$. Very fine. 27,28 . Very hot and sultry, 29. Heavy rain: excessively boisterous in the afternoon. 30. Cloudy: showery. 31 . Very fine: showery.
Boston.--July 1. Cloudy.
2, 3. line.
4-7. Cloudy.
8. Finc. 9. Cloudy. 10, 11. Fine. 12. Cloudy. 13. Cloudy: rain with thunder and lightning P.M. 14. Cloudly: rain early A.M. 15.Cloudy: rain early A.M.: rain P.M. with thunder and lightoing. 16,17. Fine : rain P.M. 18. Cloudy : rain P.M. 19. Fine. 20. Cloudy: rain A.M. and P.M. $21-25$. Cloudy. 26. Fine: rain A.nr 27. Cloudy. 28. Rain. 29. Rain and stormy. 30. Cloudy and stormy. 31. Fine: rain with thunder and lightning p.ur. 